\title{
Copies and Random Decision: a proposal to peacefully solve the conflict around looted art
}

Bruno S. Frey ${ }^{1}$

I propose a novel approach to deal with the conflict between the present owners and the original owners of looted art. The procedure is based on perfect copying (which is possible today due to digital techniques) and random procedures (which are a means to achieve a fair outcome).

\section{Restitution}

The crime of "looted art" has been intensively discussed with respect to the Nazi-regime, which appropriated a large number of art works owned by Jews during World War II and before. This crime has been subject to a large literature (see e.g. Gaudenzi 2021, Oost 2018, Simpson 1997). Some of the stolen objects were immediately restituted after the war, some of them only in the course of time, and some not at all. Consequently, these works of art have been dubbed "last prisoners of war" (Thompson 2021), and the United States Holocaust Memorial Museum features an extensive exhibition on looted art by the Nazi-regime.

There are many legal issues involved in this conflict (e.g. Hay 2017, O'Donnell 2011, O'Donnell 2017), many of which remain unsolved. An open issue is whether the owners of the art work sold them voluntarily before emigrating (Hickley 2021). Another is whether art works acquired at an official auction remain in the possession of the acquirer or whether they are also subject to restitution claims. These issues are solved differently in different countries (e.g. Rodman 2008, Roodt 2013).

An intensive debate also erupted about handling works of art from former colonial countries and now presented in Western museums (e.g. Gaudenzi and Swenson 2017, Yates 2016). A prominent example are the Benin bronzes. They were appropriated in 1897 by the English during a colonial intervention. Some of the bronzes were in a bad condition, were saved, and have been carefully restored. They were auctioned in

\footnotetext{
${ }^{1}$ Bruno S. Frey is Permanent Visiting Professor at the University of Basel and Research Director of CREMA - Center for Research in Economics, Management and the Arts, Switzerland. This paper is a strongly modified and extended version of an unpublished paper with Andre Briviba, The Conflict about the Restitution of Art Works: A Solomonic Proposal, and of a short article by the author in German, Lasst das Los entscheiden! in the Magazin, Tagesanzeiger, Zurich.
} 
London and have since been exhibited in various museums, many of them in the British Museum (Hicks 2020, Wood 2012).

Two opposing positions dominate this debate. One side claims that these works of art were looted and should be restituted to the countries from which they originate. The other side argues that some of these works of art were traded for money on official art markets, and that they therefore were not stolen. These works of art have been preserved because they were well taken care of the West mostly in museums. Possibly, they would otherwise no longer exist. Moreover, some of the states that reclaim the artworks are dictatorships, which should not be supported. The conflict seems to be insolvable as the discussion is more based on ideology than on serious considerations. The conflict has also reached the political sphere. In the case of the Benin bronzes the issue has been transferred to the governments of the United Kingdom and Nigeria (which, somewhat questionably) represents the interest of the former state of Benin.

The economics of art and culture (Throsby 2010, Towse 2010, Frey 2019) deals intensively with such conflicts. These conflicts reflect scarcity: they arise because it is taken for granted that there is only one "original" work of art, which various actors want to own. Standard economics compares the benefits and costs of different allocations of such scarce goods. This approach is, however, faced with difficult valuation problems on both the benefit and cost sides. In the cases discussed, there does not seem to be a solution acceptable to the present and former owners of the respective objects of art. Depending on the outcome, one part is a winner, the other a loser.

\section{A radical proposal}

I propose a different, novel approach based on perfect copying and random procedures. Photogramming and the exact measurement of objects by lasers make it possible to exactly replicate an art object. The digital process enables precise reproductions of cultural goods (e.g. Gupta, Sharma and Kumar 2019, Barbieri, Fabio and Muzzupappa 2017). It has been empirically analyzed whether viewers are able to differentiate between originals and reproductions. A careful analysis Grüner, Specker and Leder (2019, p.148) "...did not find an effect of genuineness" (see also Locher, Smith and Smith 1999, 2001, Brieber, Leder and Nadal 2015, Mastandrea, Bartoli and Bove 2007, 2009).

These empirical results stand in conflict with the received view that originals differ from copies because they have a specific "aura". This view has been forcefully advanced by Benjamin (1939) but is most questionable in today's world where viewers can no longer distinguish between originals and replications due to the advances of digitalization. Copies have by now been largely accepted as valuable means to provide art to a larger audience. For instance, Delft has established a museum solely consisting of copies of works by Vermeer. Similarly, at the Lascaux caves the pre-historic paintings were reproduced in a newly built cave to the satisfaction of visitors (for more cases see Frey and Briviba 2021). 
The digital techniques used to replicate originals allow us to expand the supply of art goods, thereby mitigating their scarcity and enabling an additional number of people to see the artworks. This technological advance turns the conflict between the various parties into a positive sum game for society. The proposal therefore may help to overcome the allocation conflict.

My proposal consists of three steps:

(1) The works of art claimed by two parties are identically copied. The respective costs are shared by the two parties.

(2) The original and the replica are placed next to each other without revealing which one is the original.

(3) A random mechanism, or a decision by lot, (e.g. Stone 2011, Frey and Steiner 2014, Osterloh and Frey 2019) decides which of the two parties may freely choose which of the two exhibits they want. The random selection must be correctly done and must not be rigged. If the representatives of the original location of the artwork are the winners, they can choose which of the two objects of art they want to have. The same holds, if the representatives of the Western museums are randomly chosen.

As the winner of the random selection can choose between the two works of art without any restriction both parties should be satisfied. The non-winning party, which gets the remaining artwork, can also be happy since the art works are identical, as the replica is indistinguishable from the original. Following this approach for all works of art claimed by various parties, the random procedure guarantees that each party will make the first choice an equal number of times. This procedure makes it possible to overcome a seemingly unbridgeable social conflict.

\section{Possible Counterarguments}

Various counter-arguments can be raised. Probably the most important one is whether identical copies of statutes and images are possible. There exists much empirical evidence that this is indeed the case from the point of view of both lay and professional spectators. Even well-trained experts in culture and art historians cannot distinguish what is the original and what is the copy. This would at best be possible by experts in chemistry and physics who have to dissect the art objects. Even if it was possible to identify a replication by non-invasive or minimally invasive techniques, it is still questionable whether the definition of what "art" is should be left to the natural sciences rather than to art experts and viewers. The essential point in our context is whether viewers can identify a difference between the original and a replication. The empirical evidence cited above strongly suggests that this is not the case for good copies.

Lay viewers often do not mind whether an art object is an original or a copy. This even holds when they are explicitly informed that certain art objects are replications. The prehistoric paintings in the caves of Lascaux, Altamira and Chauvet provide an example. To preserve the original drawings, they had to be copied and presented in new 
caves. According to research (Frey and Briviba 2021), 90 percent of visitors perceive the copies as authentic replications, and nevertheless fully enjoy the visit. In some cases, art experts may be able to distinguish the original from the replication while people not trained in the arts did not rate genuine artworks differently from reproductions (Grüner, Specker and Leder 2019). However, the conflicts here considered refer to art viewers in general and not to art-trained people.

My proposal may also be rejected because people are unfamiliar with random mechanisms and intuitively tend to reject them, particularly in the context of art. However, history shows that random procedures have a pacifying effect. For example, they were used with good effect in classical Athens, for the election of the Doge in Venice, as well as in flourishing North Italian medieval city states (e.g. Zeitoun, Osterloh and Frey 2014).

\section{Conclusion}

The pacifying effect of random choice has been strongly put forward by enlightened sage persons. Solomon in the Old Testament praises aleatoric procedures as an effective manner to settle conflicts: "The lot puts an end to the disputes, and between the powerful it decides".

To introduce perfect replicas and random devices may be opposed by actors who have an interest in maintaining the conflict. They may do so for political reasons or because they benefit from the conflict. This may be the case because they want to maintain their market value as art experts. The idea may also be opposed for purely political reasons by actors profiting from the status quo.

The basic idea here proposed can be adapted to specific conditions in various ways. Thus, the random decision might be applied directly to the choice between original and replica. While this simplifies the procedure, it leaves no room for an active participation of the former and present owner of an art object.

The proposals here advanced can be applied to many other conflicts in a similar way as to the allocation of works of art. An example could be the division of property such as houses or cars in the case of divorce.

Proposals to overcome a deep-seated conflict are always problematic and difficult to solve. New procedures such as the one here advanced may be helpful and should seriously be considered. 


\section{Gardener Comments}

\section{Ted Wade:}

The authors are much too glib about whether we can make high fidelity 3-D copies out of atoms and not bits. The two references on copying did not begin to address this. Even a miracle-level 3D copy machine would not be able to reproduce the chemical subtleties that evidence the age and provenance of materials, let alone subtleties like brush technique, or invisible palimpsests. Further, I personally think that no hard-headed lawyer or politician would accept the process. And, if you could make one good-enough copy then you could make a million, so there is very reduced satisfaction in holding a copy, or maybe even the original. However, I vote yes on publication. The paper could stimulate research on the philosophical nature of identity, or on some aspect of behavioral economics. It might also lead to defining a "consolation prize" for the loser in an ownership conflict. E.g., one could sue for a perpetual right for the latest and best available digital scan, authenticated with a digital non-fungible token, accompanied by some money to print a copy for public display.

\section{Sergey Samsonau:}

While a process of making a perfect copy is not available, there may be some ways to limit an examination of two pieces (original and copy). For example, both pieces (an original and a copy) can be put in locked transparent boxes, making it harder to figure out authenticity. Although I don't think this method has a chance of broad acceptance, it may work in some cases.

This seed has the potential to focus the attention of researchers on adjacent questions. For example, will people care if they see "an original" in a museum or see " $50 \%$ chance original"? Will the existence of one copy bring more or less attention to this piece of art (for example, people may find it interesting to visit both places, make their judgments, discuss that on social media)? How do the monetary value and visitors' perception change when a piece of art has a certain probability of being authentic: $50 \%, 33 \%$, $20 \%$ ?

\section{Phil Wilson:}

My objection to the paper concerns the author's cherry-picked definition of "perfect copying". They have chosen a definition which supports their argument but which is not universally accepted in common usage and in particular is highly unlikely to be accepted by the very people it claims to help, namely those involved in a dispute over ownership. To whit, the implied idea that equal worth will be given by a rational agent to a copy of a work of art which is merely visually indistinguishable from the original is highly dubious. 
To know that the hand of a master touched the canvas or the stone, that those pigments were mixed by her hand hundreds of years ago, or that those chisel marks were made by his instrument in his hand, utterly change the worth of a piece. To know that the physical material which constitutes a work of art has survived, though in a changed form due to age and decay, for perhaps many hundreds of years adds incalculable valuable.

\section{Phil Filippak:}

This Seed encourages interesting lines of thoughts but only in regard to itself, i.e. provokes a path of reasoning that locks upon itself. Despite this being an intriguing speculation per se, I don't see in what possible way it could advance scientific progress.

As I see it, the core motivation behind this Seed is to provide a mechanism of resolving conflicts but, as I point out in the second objection in the corrections section, it may lead to a more serious conflict - mainly because the function that defines which Ship of Theseus is authentic and which is not is defined for every individual separately and is not a part of the objective truth.

\section{Richard Roos:}

At first I did not see at all how this article could advance science. It describes an interesting method for resolving conflicts worth looking into it - but this is not related to science in any direct way.

After some thought l've found that it is possible to use scientific approach in bettering replica-making technologies, and developing better methods to recognize such replicas. This is somewhat similar to GANs, generative adversarial networks.

But again, we already have such replica-generating and replica-detection progress going on as a battle between forgers and museum experts. So my final verdict is that while this idea does seem to be of some value, it does not bring novelty into science, or at least I don't see how.

\section{Roger's Bacon:}

I think I feel as many reviewers might feel - I don't necessarily agree with the proposal and I don't really think it should be done, but I find the article interesting for a number of reasons (see below) and therefore I vote yes, with many reservations (which I will spell out in corrections as I feel these need to be addressed before publication).

I like this proposal because it offers a novel randomness-based solution to a frequently insoluble social issue. The "Randomness in Science" example article on Seeds argues 
that because of our natural aversion to randomness and unpredictability we underutilize randomness-based strategies in science and culture; this proposal fits very well with that thesis. The author touches on the use of random strategies in resolving disputes throughout history, but it would be interesting to have further discussion/speculation on how we might use randomness (maybe with a copying mechanism) to solve other societal issues. For example, there has been some positive research on the use of randomness in promotions (or randomly choosing who makes the promotion decision) - see the relevant section in the 2012 article "Strange but true: science's most improbably research" in the guardian.

If both sides agree to this proposal, does that mean we - the people of a country, or humanity as a whole - should allow it to proceed? Original owners die and the art lives on - in a sense, art is owned by all of humanity. Do we want to cheapen the art by creating duplicates? Many of us may feel that part of the value of the art comes from it being one-of-a-kind, of knowing that the master's hand graced this particular canvas. Why should the parties involved in the dispute have the right to make a copy?

I think many people (myself being one of them) might reject this proposal because of an intuitive aversion to the act of making identical replicas. There is something about perfect copies that weirds us out. It's very unnatural - we almost never see two things that are exactly identical in nature, except perhaps identical twins, but even they will have small differences. This is why we have the "evil twin" trope and why mirrors are often used to creepy effect in horror movies.

"Mirrors and copulation are abominable, since they both multiply the numbers of men" -Jorge Luis Borges

\section{R. Sal Reyes:}

Although it doesn't seem likely that this kind of solution would ultimately be acceptable to parties involved in an art dispute-because collectors typically place such value on possessing an "original" work that a replica (no matter how perfect) would likely be seen as a clearly inferior option. Nonetheless, that is partly what makes this an intriguing proposal-because it begs the question: if the objects truly are exact replicas, why should it really matter to either party? What is it about the origins of identical things that should make us value one more than the other?

It might also be interesting (if one could conduct an experiment employing this kind of solution) to see if there are differences in the parties' satisfaction with this kind of negotiation if you compared parties' who knew which of the two was receiving the original and parties who were not informed which of the two actually was given the 
original (in a kind of blind random selection that allows both parties to believe they may or may not possess the original). An intriguing follow-up would be to track that satisfaction over time, to see if the value of possessing the "original" (or the value of certainty of origin) persists or wanes.

Finally, one might consider using this kind of negotiation technique (minus the exact replicas) in a different (but possibly equally contentious) setting like divorce settlements- randomly distributing contested assets between spouses. For example, contested assets might be grouped into sets that the parties agree have equal value (a negotiation process that could account for sentimental or convenience value in addition to just monetary value when grouping the assets) and then the sets of equivalent assets could be divided randomly between parties. In this case, it would also be interesting to gauge differences in the parties' satisfaction with the results in comparison to non-random negotiated asset division.

\section{Vincent:}

This article puts together two ideas: one that's scientific but not novel (using photogramming and laser to make identical replicas of artifacts), and one that's novel but not really scientific (making replicas to solve government and foreign relation problems), which does not necessarily adds up to a novel scientific idea. I think this article contains some value, but not quite aligned with the main focus of this journal -- I don't quite see how this idea can advance the field of science. Sure this is a new idea, but I can't really see what scientific development can be made based on this idea. I might change my opinion if the author can explain why this is a "seed" rather than a "leaf".

\section{Anonymous:}

After the sentence "This may be the case because they want to maintain their market value as art experts", the author may include a short explanation describing the trade-off between maintaining the market value of experts as compared to the potential societal value brought about through an increased number of people having access to such artwork.

\section{Rohit:}

I find the reliance on copying interesting here, if only because we're in the middle of perfectly copied artwork made artificially scarce (NFTs). In essence you're proposing an anti-NFT. I'd like to see some exploration of that, as well as the actual mechanisms of copying that exist - i.e., what types of work can we do this with, and how well. 


\section{Anonymous:}

I wonder whether or not the value of an artwork in part depends on its scarcity -- that is to say, whether or not the very action of replicating the artwork to produce an "indistinguishable" copy takes away the artworks value -- economical value, historical value, etc.

\section{Anonymous:}

Should auctioned art be involved in legal procedures of restitution?

\section{Anonymous:}

I agree that there is no value in the notion of original and duplicate/forged art. However, changing public opinion on that front may be difficult, as most synonyms of the word "copy" have a negative connotation.

\section{Rubidium:}

I'm not sure if this article really counts as advancing science in any way; the problem it addresses is more of a problem in applied ethics or aesthetics. But, since it is a valuable contribution in those fields, I choose to say that it should be published in "Seeds of Science".

As to the fundamental premise of the article ... I'm afraid that, in the art world, authenticity is valued much more than the author of this article seems to think. Most likely, the author's proposal would not be welcomed by either the current holders of the looted art, or the original owners / representatives of the creator's culture. Having the chance to own an exact duplicate of a work of art would, unfortunately, be considered by most museums and gallery owners to be equivalent to having a color photocopy of the artwork.

That being said, I see no reason why the author's idea would not work as a solution for two parties that agree to its implementation in their own particular case. I think the author's idea is a valuable and valid attempt to provide a solution to a seemingly intractable problem.

\section{Oemac:}

Suppose the government of 2 countries are arguing about a looted art.

First, probably nobody prefer the copied art more than the original one, so l'Il just ignore this situation. Then:

1. If both governments are fine with only having a copy, and both have no preference between the copy and the original one, then it'll be simpler if the government that doesn't have the original one just take the copy. 
2. If both governments are fine with only having a copy, but one of the governments prefer the original one than the copy, then it'll be better if the country that have preference take the original one.

3. If both governments are fine with only having a copy, but they both prefer the original one than the copy, then the government that has the original one won't agree to give it to the other government.

4. Else, at least one of the governments won't accept the method in your article, because it doesn't want the copy.

Therefore, I'm not sure whether any governments will accept this method. However, I guess it'll be great if this method can be enforced in situation 3 sometimes.

\section{Wendy Wong:}

While I don't necessarily agree with what the author is arguing, I think it deserves to be published because it's thought-provoking. It offers an interesting take on how to handle looted/stolen art restitution- a complicated (and often polarizing) area of law. He's missing a couple of counterarguments others have brought up in looted art restitution, but nonetheless, it's a piece worthy to be on SoS.

\section{References}

Barbieri, Loris (2017). Virtual museum system evaluation through user studies. Journal of Cultural Heritage, 26: 101-108.

Benjamin, Walter (1939). Das Kunstwerk im Zeitalter seiner technischen Reproduzierbarkeit. Gesammelte Schriften, Volume 1. Frankfurt am Main: Suhrkamp: 471-508. English translation: The work of art in the age of reproducibility. In: M. Jennings (ed.), The work of art in the age of its technological reproducibility. Cambridge, Mass.: Grey Rooms and Massachusetts Institute of Technology: 11-37.

Brieber, David, Helmut Leder and Marcos Nadal (2015). The experience of art in museums: An attempt of dissociate the role of physical context and genuineness. Empirical Studies of the Arts, 33: 95-105.

Frey, Bruno S. (2019). Economics of Art and Culture. Cham: Springer.

Frey, Bruno S. and Andre Briviba (2021). A policy proposal to deal with excessive cultural tourism. European Planning Studies, 29 (4): 601-618.

Frey, Bruno S. and Lasse Steiner (2014). God Does Not Play Dice, But People Should: Random Selection in Politics, Science and Society. SSRN. https://ssrn.com/abstract=2407896 or http://dx.doi.org/10.2139/ssrn.2407896. 
Gaudenzi, Bianca (2021). The 'Return of Beauty'? The politics of restitution of Nazi-looted art in Italy, the Federal Republic of Germany and Austria, 1945-1998. European Review of History: Revue européenne d'histoire, 28 (2): 323-346

Gaudenzi, Bianca and Astrid Swenson (2017). Looted art and restitution in the twentieth century - Towards a global perspective. Journal of Contemporary History, 52 (3): 491-518.

Gupta, Varum, Akhil Sharma and Praveen Kumar (2019. Restoration of artwork using deep neural networks. Evolving Systems: 1-8.

Grüner, Susanne, Eva Specker and Helmut Leder (2019). Effects of Context and Genuineness in the Experience of Art. Empirical Studies of the Arts, 37 (2): 138-152.

Hay, Bruce L (2017). Nazi-Looted Art and the Law. Cham: Springer.

Hickley, Catherine (2021). Did the Nazi Force Art Sales? The Question Lingers 88 Years.

New York Times. Retrieved from https://www.nytimes.com/2021/07/06/arts/design/nazis-art-forced-sales.html

Hicks, Dan (2020). The British Museums: the Benin Bronzes, colonial violence and cultural restitution. London: Pluto Press.

Locher, Paul J., Lisa F. Smith and Jeffrey K. Smith (1999). Original paintings versus slide and computer reproductions; A comparison of viewer responses. Empirical Studies of the Arts, 17: 121-129.

Locher, Paul J., Lisa F. Smith and Jeffrey K. Smith (2001). The influence of presentation format and viewer training in the visual arts on the perception of pictorial and aesthetic qualities of paintings. Perception, 30: 449-465.

Mastandrea, Stefano, Gabriella Bertoli, and Giuseppe Bove (2007). Learning Through Ancient Art and Experiencing Emotions With Contemporary Art: Comparing Visits in Two Different Museums. Empirical Studies of the Arts, 25 (2):173-191

Mastandrea, Stefano, Gabriella Bertoli, and Giuseppe Bove (2009). Preferences for ancient and modern art museums. Visitor experiences and personality characteristics. Psychology of Aesthetics, Creativity, and the Arts, 3: 164-173.

O'Donnell, Thérèse (2011). The Restitution of Holocaust Looted Art and Transitional Justice: The Perfect Storm or the Raft of the Medusa? European Journal of International Law, 22(1): 49-80.

O'Donnell, Nicholas M. (2017). A Tragic Fate: Law and Ethics in the Battle Over Nazi-Looted Art. Art Antiquity \& Law, 22 (4): 363-366. 
Osterloh, Margit and Bruno S. Frey (2019). Dealing with Randomness. Management Review, 30 (4): 331-345.

Oost, Thabita I. (2018). Restitution Policies on Nazi-Looted Art in the Netherlands and the United Kingdom: A Change from a Legal to a Moral Paradigm? International Journal of Cultural Property, 25 (2): 139-178.

Rodman, Lauren F. (2008). A Wakeup Call for a Uniform Statute of Limitations in Art Restitution Case. Entertainment Law Review, 15: 203-226.

Roodt, Christa (2013). Restitution of art and cultural objects and its limits. Comparative and International Law Journal of Southern Africa, 46 (3): 286-307.

Simpson, Elisabeth (1997). The Spoils of War - World War II and Its Aftermath: The Loss, Reappearance, and Recovery of Cultural Property. New York: Harry N. Abrams in association with the Bard Graduate Center.

Stone, Peter (ed) (2011). Lotteries in Public Life: A Reader. Exeter: Imprint Academic.

Thompson, Monica May (2021). The Last Prisoners of War: How Nazi-Looted Art is Displayed in U.S. Museums. Geifman Prize in Holocaust Studies. https://digitalcommons.augustana.edu/geifmanprize/17

Throsby, David (2010). The Economics of Cultural Policy. Cambridge: Cambridge University Press.

Towse, Ruth (2010). A Textbook of Cultural Economics. Cambridge: Cambridge University Press.

Wood, Paul (2012). Display, Restitution and World Art History: The Case of the 'Benin Bronzes'. Visual Culture in Britain, 13 (1): 115-137.

Yates, Donna (2016). The Global Traffic in Looted Cultural Objects. Oxford Research Encyclopedia of Criminology and Criminal Justice. https://doi.org/10.1093/acrefore/9780190264079.013.124

Zeitoun, Hossam, Margit Osterloh and Bruno S. Frey (2014). Learning from Ancient Athens: Demarchy and Corporate Governance. Academy of Management Perspectives, 28 (1): 1-14. 